\title{
Acute respiratory infections among under-five children from households using biomass fuel in Ethiopia: systematic review and meta-analysis
}

\author{
Zewudu Andualem, ${ }^{1}$ Zelalem Nigussie Azene, ${ }^{2}$ Awrajaw Dessie, ${ }^{1}$ Henok Dagne, ${ }^{1}$ Baye Dagnew ${ }^{3}$ \\ ${ }^{1}$ Department of Environmental and Occupational Health and Safety, Institute of Public Health, College of Medicine and \\ Health Sciences, University of Gondar \\ ${ }^{2}$ Department of Women's and Family Health, School of Midwifery, College of Medicine and Health Sciences, University of \\ Gondar \\ ${ }^{3}$ Department of Human Physiology, College of Medicine and Health Sciences, University of Gondar, Ethiopia
}

\begin{abstract}
Acute respiratory infections are a serious public health concern across the globe, they are, however, prominently present in Sub-Saharan Africa. In Ethiopia, different primary studies were conducted in regard to the link between household biomass fuel use and acute respiratory infections among under-five children. However, there is no national study on the association between household biomass fuel use and acute respiratory is infections among under-five children. Thus, the aim of this systematic review and meta-analysis to estimate the pooled prevalence of acute respiratory infections and their predictors among under-five children in Ethiopia.

The systematic review was reported according to the Preferred Reporting Items for Systematic Reviews and MetaAnalysis (PRISMA) guideline. We systematically searched the databases: PubMed/Medline, Cochrane library, Google Scholar, Web of Science, and Scopus were searched to access potentially relevant articles conducted in Ethiopia about acute respiratory infections among under five children. Stata/SE 14.00 statistical software was used for analysis and the pooled prevalence with $95 \%$ confidence interval (CI) were presented using tables and forest plots. To assess the heterogeneity among studies, I square $\left(\mathrm{I}^{2}\right)$ tests were used. Publication bias was checked by Begg's and Egger's regression test. The random effects meta-analysis model was employed to estimate the pooled prevalence and predictors of under-five acute respiratory infections

A total of 7 studies with 8,529 study participants were included in this meta-analysis. The pooled prevalence of acute respiratory infection among under five children was $17.75 \%$ (95\% CI: 16.95, 18.55). Child holding during cooking (OR: $2.84,95 \%$ CI: $1.48,5.47$ ) and using unclean sources of energy for cooking (OR: $0.38,95 \%$ CI: $0.21,0.70$ ) were identified predictors of under-five children acute respiratory infection.

In the current study, the pooled prevalence of acute respiratory infection among under-five children was relatively high. Child holding during cooking and using unclean sources of energy for cooking were significantly associated with under-five acute respiratory infections. Therefore, the policies and regulations enacted should address the barriers that impede the development of clean and efficient energy sources.
\end{abstract}

Key words: Acute respiratory infection; biomass fuel; meta-analysis; systematic review; under five children; Ethiopia.

Correspondence: Zewudu Andualem, Department of Environmental and Occupational Health and Safety, Institute of Public Health, College of Medicine and Health Sciences, University of Gondar, Ethiopia.

E-mail: zewuduandualem12@gmail.com

Contributions: ZA, conceptualization, formal analysis, methodology, software; ZA, HD, BD, data curation; ZNA, AD, validation; ZA, HD, BD, ZNA, AD, manuscript original draft, review and editing. All the authors have read and approved the final version of the manuscript and agreed to be accountable for all aspects of the work.

Conflict of interest: The authors declared that they have no competing interests.

Availability of data and materials: All data generated or analyzed during this study are included in this article..

Ethics approval and consent to participate: Not applicable because no primary data were collected.

Consent for publication: Not applicable. 


\section{Introduction}

Acute respiratory infections (ARIs) are dichotomized as upper respiratory tract infections and lower respiratory tract infections. The upper respiratory tract comprises of the airways from the nostrils to the vocal cords in the larynx. The lower respiratory tract involves the continuation of the airways from the trachea and bronchi to the bronchioles and the alveoli [1,2]. They are a considerable hardship to the health of children under five years of age in low and middle-income countries like Ethiopia [3,4]. ARI, chiefly of the lower respiratory tract, is the top cause of death among children under five years of age in such countries $[5,6]$.

Acute respiratory infections are a serious public health concern across the globe; they are, however, prominently present in Sub-Saharan Africa and are estimated to be responsible for fortytwo percent of childhood deaths [4]. The correlation between wood use, cooking, and the epidemiology of respiratory infections is a topic of interest for the active current research, but a persistent trend connecting environment, energy, and health has been already greatly obvious [7]. In Ethiopia, biomass fuels are the main sources of energy and consumption. It is the only energy used for cooking, lighting, and heating for about more than $90 \%$ of the Ethiopian population, by which $99 \%$ is originated from fuel wood, charcoal, crop residue, and leaves, fuel wood holding the first position $[8,9]$. The World Health Organization (WHO) estimates on the burden of diseases for the year 2002, Indoor Air pollution from biomass use accounted for $3.7 \%$ of the burden of disease in developing countries [10]. In Ethiopia, it is accountable for 50,320 annual deaths of under- five years of children, accounting for $4.9 \%$ of the national burden of diseases [11].

There was no nationwide study assessing the link between household biomass fuel use and acute respiratory infections among under-five children. Hence, this systematic review and meta-analysis aimed to estimate the pooled effect of household biomass fuel use on acute respiratory infections amongst children under five years of age in Ethiopia using the available studies. The findings of this systematic review and meta-analysis will highlight the effect of household biomass fuel use on the acute respiratory tract infections in children with the implications of applying evidence-based interventions through accessing to clean fuel for cooking, make sure cost-effectiveness, adopting prompt measures with collaborative efforts from families, the community, policymakers, health workers, governmental and non-governmental organizations, and other stakeholders to reduce drastically the burden of ARIs in a country.

\section{Study design and setting}

A systematic review and meta-analysis were conducted to estimate the pooled prevalence of acute respiratory infection and its association with household biomass fuel use among under-five children in Ethiopia. Ethiopia is located in Eastern Africa. Currently, the Ethiopian population is estimated to be 114,963,588 with $21.3 \%$ living in urban areas [12].

\section{Reporting}

The results of this review were reported according to the Preferred Reporting Items for Systematic Reviews and MetaAnalysis (PRISMA) checklist [13] (Supplementary file 1). It is registered in the Prospero database available at https://www.crd.york.ac.uk/PROSPERO/\#searchadvanced (PROSPERO 2020: CRD42020128659).

\section{Eligibility criteria}

\section{Inclusion criteria}

- Study setting: Studies done in Ethiopia.

- Study participants: Studies conducted among under-five children.

- Publication status: All published and unpublished articles.

- Language: Only studies published in English were included

- Types of studies: Studies that employed observational study design.

- Publication date: The authors included articles published until April 30, 2020.

\section{Exclusion criteria}

Despite the above-mentioned preset eligibility criteria, articles in which we were unable to access the full-texts after two email contacts of the principal investigator of the particular study were excluded from the final analysis.

\section{Search strategies}

An extensive search was done from PubMed/Medline, Cochrane library, Google Scholar, Web of Science, and Scopus were used to access potentially relevant articles done on acute respiratory infections among under-five children in Ethiopia. Gray literature/unpublished articles of observational studies were searched through the review of reference lists and input of content experts. Besides, to find unpublished papers relevant to this systematic review and meta-analysis, some research centers, including the Addis Ababa University digital library were searched. The core search terms and phrases were indoor air, household air, biomass, smoke, fuel, stove, respiratory infection, respiratory tract infection, respiratory illness, respiratory symptoms, child, children, Ethiopia. The following search strategy was applied separately and in combination using Boolean operators [(Indoor air [MeSH Terms] OR Household air) AND (biomass OR smoke OR fuel OR stove) AND (Respiratory infection [MeSH Terms] OR respiratory tract infection OR Respiratory illness OR Respiratory symptoms AND (child OR children) AND (Ethiopia)].

\section{Study selection procedures}

Studies identified by our search strategy were retrieved and managed using Endnote X7 software to remove duplicate studies. Two independent authors screened the title and abstract. The disagreement was handled based on established article selection criteria. Three independent authors $[\mathrm{ZA}, \mathrm{HD}, \mathrm{BD}]$ conducted the fulltext review.

\section{Measurement of outcomes}

\section{Outcome definition}

This study has two main objectives. The primary objective is acute respiratory infection (ARI) which was defined as ARI to include any combination of the following symptoms: cough with or without fever, blocked or runny nose, sore throat, and/or ear discharge with infection of the lungs $[11,14]$.

The second objective of this study is to identify the predictors of acute respiratory infection among under-five children. The predictors included in this review were: sex (male/female), ventilation (yes/no), child holding during cooking (yes/no) and types of fuel used for cooking (clean/unclean).

\section{Data extraction and quality assessment}

Data from included articles were extracted using a standardized data extraction format, adapted from the Joanna Briggs Institute (JBI), by two authors [ZNA, HD, ZA]. For the first outcome (prevalence of acute respiratory infection), the data extrac- 
tion format included primary author, study design, sample size, and first author name for the prevalence of acute respiratory infections among under-five children, publication year, region(s) of the country where the study was conducted, sample size, and response rate. For the second outcome (predictors), data were extracted in a format of two-by-two tables, and then the log odds ratio for each factor was calculated based on the findings of the original studies.

Two authors (HD, BD) independently assessed the risk of bias for each original study by using a quality assessment checklist for prevalence studies adapted from Hoy et al. [15] (Table 1).

\section{Data processing and analysis}

Pertinent data from every primary study were extracted using Microsoft Excel format. Data were then exported to STATA Version 14 statistical software for analysis. Heterogeneity of the studies was assessed by computing p-values of $\mathrm{I}^{2}$ statics [16] and publication bias was checked objectively via Egger's and Begg's regression test $[17,18]$. In the current meta-analysis, logit transformation was used. The pooled proportion was estimated by using the back-transform of the weighted mean of the transformed proportions, using arcsine variance weights for the fixed-effects model and DerSimonian-Laird weights for the random-effects model [19]. Point prevalence, as well as $95 \%$ confidence intervals, was presented in the forest plot format. For the second outcome, a log odds ratio was used to determine the association between predictors and the outcome variables.

\section{Results}

\section{Characteristics of included studies}

Initially, 1,348 articles were retrieved reporting prevalence and predictors of household biomass fuel use and acute respiratory infections among under-five children using the range of databases previously described. After duplication removed, 703 studies were remained, 413 studies were excluded by title and 279 studies were excluded by reading abstracts. Finally, 11 studies were screened for full-text review, and 7 were met the eligibility criteria and included in the final meta-analysis (Figure 1).

\section{Description of included studies}

As depicted in Table 1, the 7 included studies were cross-sectional study design and published from 2011 to 2020. In the current meta-analysis, 8,529 study participants were included to determine the pooled prevalence of acute respiratory infections among under- five children. The smallest sample size was reported 150 [20], whereas, the largest sample size was reported 5,830 [21]. The lowest prevalence was reported in Addis Ababa [22], whereas the highest prevalence was reported in Southern Nation Nationality and Peoples Region (SNNPR) [20]. In the present meta-analysis, two Ethiopian regions and one administrative town were represented. Three of the studies were from SNNPR [20,23,24], two from Amhara [21,25], two from Addis Ababa [11,22]. Most of the studies had a $100 \%$ response rate. No studies were reported from the rest of the regions; Benishangul Gumuz, Oromia, Tigray, Gambella, Dire Dawa, Harari, Afar, and Somalia regions.

\section{Publication bias}

To check the presence of publication bias objectively Begg's and Egger's tests were employed. The results of Begg's ( $p=0.09)$ and Egger's $(p=0.45)$ tests showed that there was no statistically significant publication bias in estimating the prevalence of acute respiratory infection among under-five children.

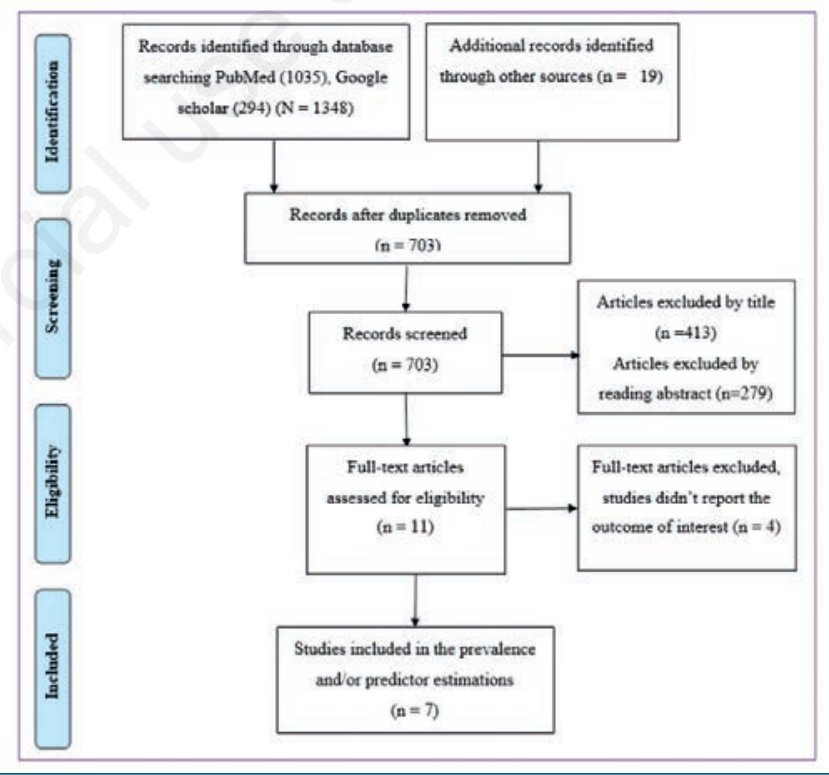

Figure 1. Flow chart for study selection.

Table 1. Characteristics and quality status of the studies included in systematic review and meta-analysis household biomass fuel use and acute respiratory infection in Ethiopia, 2020.

\begin{tabular}{|c|c|c|c|c|c|c|c|}
\hline Authors & $\begin{array}{l}\text { Publication } \\
\text { year }\end{array}$ & $\begin{array}{l}\text { Study } \\
\text { design }\end{array}$ & Region & $\begin{array}{c}\text { Sample } \\
\text { size }\end{array}$ & $\begin{array}{l}\text { Response } \\
\text { rate }\end{array}$ & $\begin{array}{c}\text { Prevalence } \\
\text { of ARI }\end{array}$ & $\begin{array}{l}\text { Quality } \\
\text { status }\end{array}$ \\
\hline Desalegn et al. (24) & 2011 & Cross sectional & SNNPR & 405 & $100 \%$ & $21.00 \%$ & Low risk \\
\hline Alemayehu et al. (25) & 2014 & Cross sectional & Amhara & 715 & $100 \%$ & $26.30 \%$ & Low risk \\
\hline Sanbata et al. (11) & 2014 & Cross sectional & Addis Abeba & 422 & $100 \%$ & $23.90 \%$ & Low risk \\
\hline Tadesse et al. (20) & 2015 & Cross sectional & SNNPR & 150 & $100 \%$ & $26.70 \%$ & Moderate risk \\
\hline Wogderesset al. (22) & 2017 & Cross sectional & Addis Abeba & 447 & $100 \%$ & $4.60 \%$ & Low risk \\
\hline Tesgaye et al. (23) & 2018 & Cross sectional & SNNPR & 560 & $96.70 \%$ & $23.80 \%$ & Low risk \\
\hline Adane et al. (21) & 2020 & Cross sectional & Amhara & 5830 & $100 \%$ & $19.21 \%$ & Low risk \\
\hline
\end{tabular}

ARI, acute respiratory infection; SNNPR, Southern Nation Nationality and Peoples Region. 
Prevalence of acute respiratory infection among underfive children in Ethiopia

The estimated pooled prevalence of under-five acute respiratory infections in Ethiopia was $17.75 \%$ (95\% CI: $16.95,18.55)$ (Figure 2). High heterogeneity was observed among included studies (I-squared 97.50\%, p<0.001). Thus, a random effect metaanalysis model was employed to estimate the pooled prevalence of under-five acute respiratory infections in Ethiopia.

\section{Subgroup analysis}

A subgroup analysis by region was computed to compare the prevalence of acute respiratory infection across regions of the country. The highest and lowest prevalence was observed in SNNPR and Addis Ababa [23.07\%, CI: (20.60, 25.54)], and [8.18\%, CI: $(6.43,9.93)]$, respectively (Table 2$)$.

\section{Predictors of under-five acute respiratory infection in Ethiopia}

The association of carrying a child at the back of mother during cooking and under-five acute respiration infection: In the current meta-analysis, we have used five studies that examined the association of child holding during cooking and acute respiratory infection $[11,20,21,23,25]$. Child holding during cooking is signif-

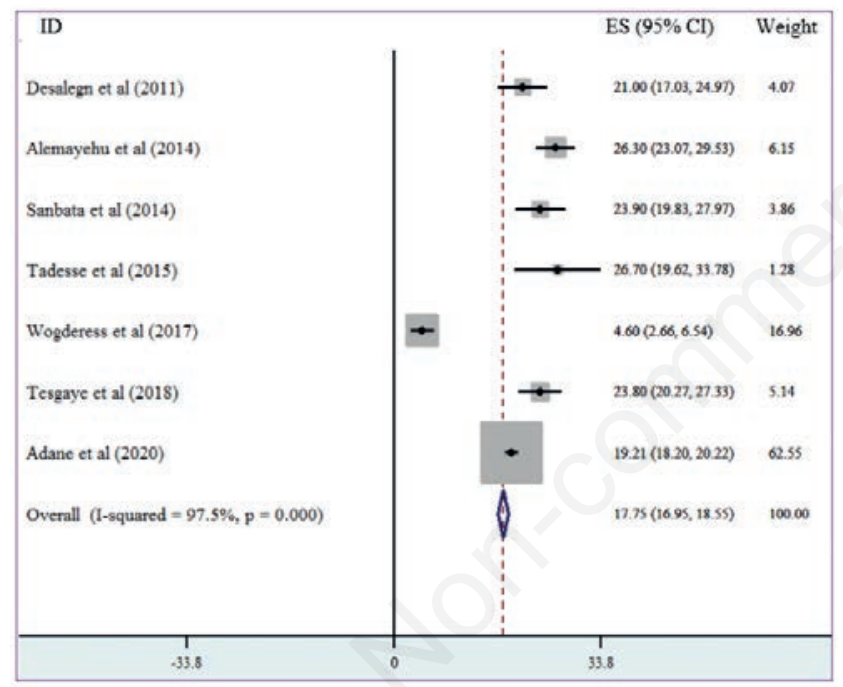

Figure 2. Forest plot for the pooled prevalence of acute respiratory infections among under-five children in Ethiopia (ES (95\% CIs) are denoted by black boxes (black lines). The combined ES estimate for all studies is represented by a blue diamond, where diamond width corresponds to $95 \% \mathrm{CI}$. Box and diamond heights are inversely proportional to precision of the ES estimate). icantly associated with childhood acute respiratory infection Those children's hold during cooking were 2.84 times more likely to suffer from acute respiratory infection than their counterparts (OR: $2.84,95 \%$ CI: $1.48,5.47$ ). The results of the test statistics indicated that high heterogeneity $\left(\mathrm{I}^{2}=79.7 \%\right.$ and $\left.\mathrm{p}=0.001\right)$ was presented across the included studies. Therefore, a random effect meta-analysis model was employed to determine the association (Figure 3).

The association of sex of a child and under-five acute respiration infection: In this meta-analysis, we used five studies to investigate the association between sex and acute respiratory infection [11,21-23,25]. As such, sex was not significantly associated with childhood acute respiratory infection (OR: 0.86 , 95\% CI: 0.71 , 1.04). The result of the test statistics indicated that low heterogeneity $\left(\mathrm{I}^{2}=24.7 \%\right.$ and $\left.\mathrm{p}=0.257\right)$ was presented across the included studies.

The association of ventilation and under-five acute respiration infection: In the present meta-analysis, we examined the association of ventilation and acute respiration infection by using five studies $[11,20,21,23,24]$. In this study, ventilation was not significantly associated with childhood acute respiratory infection (OR: $0.56,95 \%$ CI: $0.29,1.07)$. The result of the test statistics indicated that substantial heterogeneity $\left(\mathrm{I}^{2}=72.7 \%\right.$ and $\left.\mathrm{p}=0.005\right)$ was presented across the included studies.

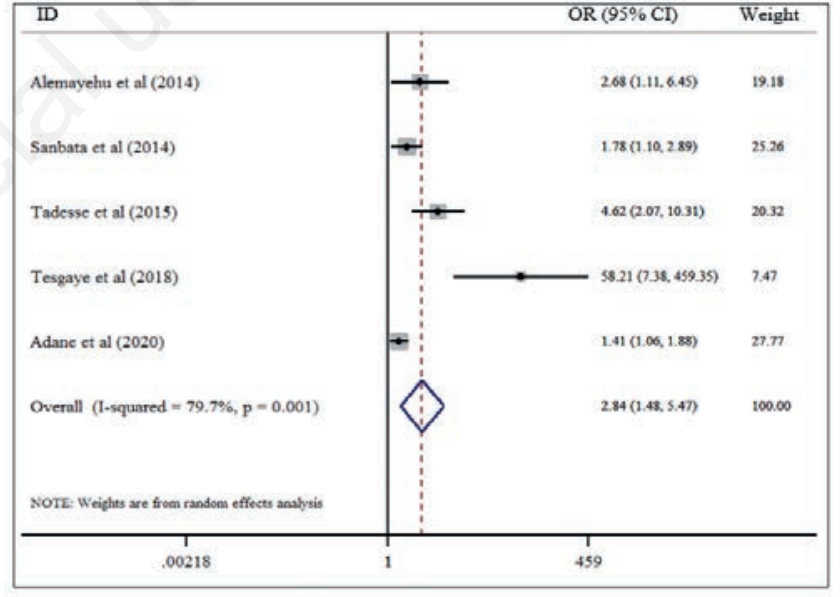

Figure 3. The pooled odds ratio of the association between child holding during cooking and under-five children acute respiratory infections in Ethiopia.

Table 2. Subgroup analysis for the prevalence of acute respiratory infection by region in Ethiopia, 2020.

\begin{tabular}{lcccc} 
Region & Number of studies included & Prevalence (95\% CI) & p & \multicolumn{1}{c}{$\mathbf{I}^{2}$} \\
Amhara & 2 & $19.84(18.88,20.81)$ & $<0.001$ & $94.1 \%$ \\
SNNP & 3 & $23.07(20.60,25.54)$ & 0.329 & $9.9 \%$ \\
\hline Addis Ababa & 2 & $8.18(6.43,9.93)$ & $<0.001$ & $<8.6 \%$ \\
Overall & 7 & $17.75(16.95,18.55)$ & $<0.001$ & $97.5 \%$ \\
\hline
\end{tabular}

SNNPR, Southern Nation Nationality and Peoples Region. 
The association of using unclean sources of energy for cooking and under-five acute respiration infection: In this meta-analysis, we used five studies to investigate the association between using unclean sources of energy for cooking and acute respiratory infection [11,21-25]. The findings of these six studies, using unclean sources of energy for cooking was significantly associated with an acute respiratory infection. The likelihood of using a clean source of energy for cooking $62.00 \%$ (OR: $0.38,95 \%$ CI: $0.21,0.70$ ) times less likely to suffer from acute respiratory infection than their counterparts who use an unclean source of energy for cooking. The result of the test statistics indicated that substantial heterogeneity $\left(\mathrm{I}^{2}=70.0 \%\right.$ and $\left.\mathrm{p}=0.005\right)$ was presented across the included studies. Therefore, a random effect meta-analysis model was employed to determine the association (Figure 4).

\section{Discussion}

Acute respiratory infection (ARI) are the leading causes of childhood illnesses that often result in serious health complications and deaths worldwide [26]. This systematic review and metaanalysis was conducted to assess the pooled prevalence of ARIs amongst children of under-five years of age in Ethiopia and its predictors. Accordingly, the study revealed that the pooled estimate ARI prevalence was $17.7 \%$ (95\% CI: $16.95,18.55 \%)$. The finding is consistent with studies conducted in Zimbabwe [27] and periurban area of Delhi, India [28] which reported a prevalence of $16 \%$ and $18.6 \%$, respectively.

On the other hand, the finding is lower than a study conducted in Bangladesh which claimed the prevalence of $20.44 \%$ [29]. Similarly, this finding is lower than the prevalence of acute lower respiratory infections among under-five children in 28 subSaharan African countries which reported 25.3\% [30]. A study conducted in Kenya reported a higher prevalence of ARI among children (69.7\%), which is higher than our pooled estimate [31]. Moreover, our finding is lower than a study conducted in urban and rural areas of Puducherry, India which reported prevalence of ARI $59.1 \%[32]$.

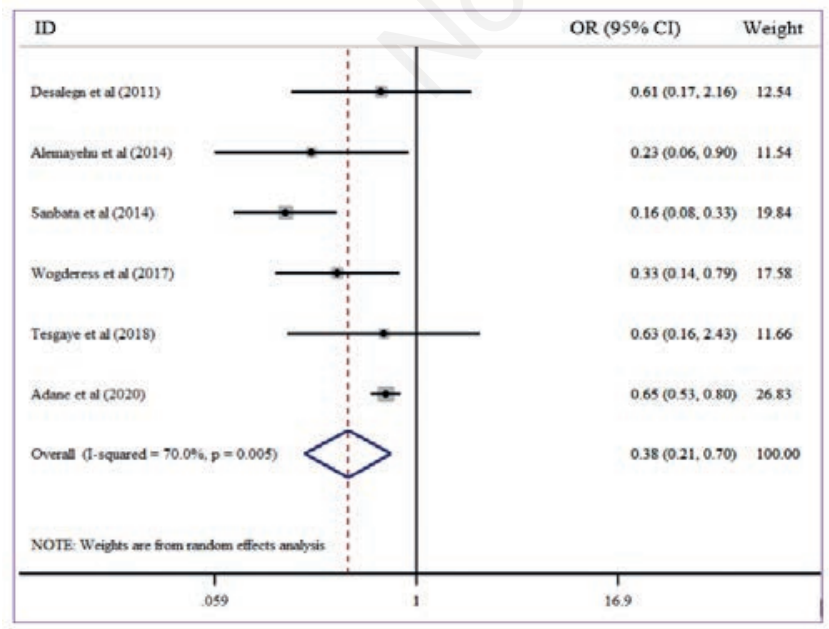

Figure 4. The pooled odds ratio of the association between using unclean sources of energy for cooking and under-five children acute respiratory infections in Ethiopia.
The possible explanation for the above-observed discrepancy between the current meta-analysis and comparable findings might be due to the difference in the sociodemographic characteristics of the study participants. The other possible explanation could be due to the difference in study design. Besides, in Ethiopia, the government has been implementing different interventions to expand the improved types of stoves in the community and rural electrification projects [33]. The health extension program in Ethiopia, which was commenced in 2003 has 16 packages, out of which 7 are related to water, sanitation, and hygiene, indoor air pollution or housing condition, and garbage disposal. These packages are very crucial to decrease the acute respiratory infection burden in children and women [34].

The pooled estimate of ARI in the current systematic review and meta-analysis was found to be higher than the reports from Ethiopian demographic and health survey (EDHS) 2005, 2011, and 2016 report, which revealed a prevalence of ARI among underfive children was $13 \%, 7 \%$, and $7 \%$ respectively [35-37]. Likewise, the finding of this study was greater than a study conducted in Tanzania 11\% [38] and from the study conducted in 40 developing nations $13 \%$ [39].

Moreover, the sub-group analysis in the current systematic review and meta-analysis depicted that the prevalence of acute respiratory infection was higher in the SNNPR (23.07\%) and the lowest was in Addis Ababa (8.18\%). The possible explanation could be the higher proportion of households in Addis Ababa are using an improved stove, had a separate kitchen from their living room, and had a good awareness of the health impact of indoor air pollution. In rural areas, however, it is common to house animals like cattle, sheep, and goats in the house, which can contribute also to the elevated prevalence of ARI. The improved sanitation and hygiene in Addis Ababa could also contribute to reduction ARI than the regions like SNNP, and Amhara region as it has been verified in the sub-group analysis [30].

In this meta- analysis, biomass fuel use was found to be significantly associated with acute respiratory infection among underfive children. The finding is consistent with scholarly articles in Enugu South East Nigeria [40], India [41], Ibadan Nigeria [42], Cameroon [43], Nepal [44,45], South India [46], Afghanistan [47]. This might be because solid fuel used in the kitchen is the main source of indoor air pollution because of the associated emissions [48]. Smoke from solid fuel contains a large number of pollutants including repairable particulate matters, toxic gases carbon monoxides, oxides of nitrogen and sulfur, aromatic hydrocarbons, benzene, formaldehyde, compounds of butane, polycyclic hydrocarbons including benzo(a)pyrene and other toxic compounds, which can cause ARI [49].

The mechanism by which fuel smoke can increase the risk of ARI is not completely understood. Animal experiments in rabbits found macrophages decreased in adherence, inhibited phagocytic rate, and compromised bacterial uptake when rabbits were exposed to wood smoke in comparison to the not exposed rabbits [50]. It's been noted that exposure to biomass smoke can lead to immune suppression, and increased bronchial reactivity, which enhances one's vulnerability to bacterial and viral diseases $[51,52]$

Exposure to the smoke from solid fuel is likely to enhance inflammatory changes and suppress defense mechanisms resulting in increased vulnerability for getting bacterial and viral infections. Similarly, under-five children are susceptible to ARI because of premature defense mechanisms and fragile airway structure $[8,53-$ 55].

Few studies reported a different finding than the current metaanalysis. These studies indicated that exposure to solid fuel smoke was not significantly associated with ARI among under-five chil- 
dren $[56,57]$. The possible justification might be in the indicated studies the majority of households were using solid fuels, therefore the variation in the sample was not substantial to find significant relationships. Hence, conducting systematic review and metaanalysis could tell us the true picture of the relationship between biomass fuel use and ARI among under-five children. Increased exposure to biomass fuel smoke also plays a strong role in increasing the chance of developing ARI among under-five children. Our finding indicated that carrying the child at the back of mothers while cooking was found to be strongly associated with the infection. Hence, on top of decreasing the utilization of biomass fuel as an energy source in Ethiopia, keeping the children away from the kitchen is advisable.

Biomass fuel is the predominant domestic fuel globally; half of the world's population is estimated to use solid biomass fuels like animal dung, crop residues, wood, and coal for cooking daily meals and heating homes. The use of biomass fuel accompanied by traditional or unimproved stoves, and poor ventilation is responsible for the generation of the high levels of pollution, measured by PM10 and priority gaseous pollutants [58].

Similarly, biomass fuel is also a major source of energy for cooking in Ethiopia. The EDHS report showed the proportion of the population using biomass fuel in Ethiopia was $99.5 \%$ in 2005 and $95.0 \%$ in 2016 [35-37]. Though slight improvement was observed in reducing biomass fuel in the last decade, it remains the dominant source of energy in the country.

The Ethiopian national energy policy underscores the promotion of clean and efficient technologies, particularly for the household sector, and sustainable bioenergy production. The policy recommends stronger governance including capable institutions and decentralized decision making on standards and their enforcement for clean cook stoves [59]. Such moves could play an important role in registering notable results in decreasing the use of polluting energy sources. However, the barriers for the development of clean energy such as lack of coordination among concerned sectors, e.g. health and energy sectors, ministerial departments, regional and national agencies, the public and the private sector, and national and international agencies. Lack of clear direction and responsibility relevant to household energy in the regulatory bodies. The cost of clean energy and the improved cooking stove is beyond the reach of the majority poor in Ethiopia. Most importantly, the community lacks adequate information on the negative health outcomes associated with the use of biomass fuel [60].

\section{Limitation of the study}

We have included articles written in English language and no other languages, we have included very limited articles and the inherent limitation cross-sectional study design. We cannot establish a causal relationship.

\section{Conclusions}

In this meta-analysis, the pooled prevalence of acute respiratory infection among under-five children was relatively high. Child holding during cooking and using unclean sources of energy for cooking were significantly associated with under five acute respiratory infections. Therefore, the policies and regulations enacted should address the barriers that impede the development of clean and efficient energy sources. As a result, the negative health impacts, like acute respiratory infection related to biomass fuel could be tackled.

\author{
Abbreviations \\ ARIs: acute respiratory infections; \\ EDHS: Ethiopian demographic and health survey; \\ ES: $\quad$ effect size; \\ OR: odds ratio; \\ SNNPR: Southern Nation Nationality and Peoples Region.
}

\section{References}

1. Simoes EA, Cherian T, Chow J, Shahid-Salles SA, Laxminarayan R, John TJ. Acute respiratory infections in children. Disease Control Priorities in Developing Countries, 2nd edition:. The International Bank for Reconstruction and Development/The World Bank; 2006.

2. Khalek EA, Abdel-Salam DM. Acute respiratory tract infections in children under 5 years of age in Upper Egypt. Int J Commun Med Public Health 2016;3:1161-6.

3. Liu L, Johnson HL, Cousens S, Perin J, Scott S, Lawn JE, et al. Global, regional, and national causes of child mortality: an updated systematic analysis for 2010 with time trends since 2000. Lancet 2012;379:2151-61.

4. Mulholland K. Childhood pneumonia mortality - a permanent global emergency. Lancet 2007;370:285-9.

5. Victora CG, Fenn B, Bryce J, Kirkwood BR. Co-coverage of preventive interventions and implications for child-survival strategies: evidence from national surveys. Lancet 2005;366:1460-6.

6. Wardlaw TM, Johansson EW, Hodge MJ. Pneumonia: the forgotten killer of children. UNICEF: 2006.

7. Wilkinson PF. Energy resources in a third world microstate: St. Lucia household energy survey. Resour Energy 1984;6:30528.

8. Smith KR, Samet JM, Romieu I, Bruce N. Indoor air pollution in developing countries and acute lower respiratory infections in children. Thorax 2000;55:518-32.

9. Bruce N, Perez-Padilla R, Albalak R. Indoor air pollution in developing countries: a major environmental and public health challenge. Bull World Health Organ 2000;78:1078-92.

10. Norman R, Barnes B, Mathee A, Bradshaw D, Collaboration SACRA. Estimating the burden of disease attributable to indoor air pollution from household use of solid fuels in South Africa in 2000. South Afr Med J 2007;97:764-71.

11. Sanbata H, Asfaw A, Kumie A. Association of biomass fuel use with acute respiratory infections among under-five children in a slum urban of Addis Ababa, Ethiopia. BMC Public Health 2014;14:1122.

12. Worldometer [Internet]. Ethiopia Population 2020. Accessed: 2020 April 24. Available from: https:/www.worldometers. info/world-population/ethiopia-population/

13. Liberati A, Altman DG, Tetzlaff J, Mulrow C, Gøtzsche PC, Ioannidis JP, et al. The PRISMA statement for reporting systematic reviews and meta-analyses of studies that evaluate health care interventions: explanation and elaboration. PLoS Med 2009;6:e1000100.

14. WHO. Programme for Control of Acute Respiratory Infections, 1992. Geneva: World Health Organization.

15. Hoy D, Brooks P, Woolf A, Blyth F, March L, Bain C, et al. Assessing risk of bias in prevalence studies: modification of an existing tool and evidence of interrater agreement. J Clin Epidemiol 2012;65:934-9.

16. Rücker G, Schwarzer G, Carpenter JR, Schumacher M. Undue reliance on I 2 in assessing heterogeneity may mislead. BMC 
Med Res Methodol 2008;8:79.

17. Egger M, Smith GD, Schneider M, Minder C. Bias in metaanalysis detected by a simple, graphical test. BMJ 1997;315:629-34.

18. Borenstein M, Hedges LV, Higgins JP, Rothstein HR. A basic introduction to fixed-effect and random-effects models for meta-analysis. Res Synth Methods 2010;1:97-111.

19. Nyaga VN, Arbyn M, Aerts M. Metaprop: a Stata command to perform meta-analysis of binomial data. Arch Public Health 2014;72:39.

20. Tadesse R. Household biomass fuel use and acute respiratory infections among younger children: An exposure assessment in Anilemo Woreda, Southern Ethiopia. PhD Thesis, Addis Ababa University; 2015.

21. Adane MM, Alene GD, Mereta ST, Wanyonyi KL. Prevalence and risk factors of acute lower respiratory infection among children living in biomass fuel using households: a community-based cross-sectional study in Northwest Ethiopia. BMC Public Health 2020;20:1-13.

22. Wogderes B. Prevalence and associated factors of acute lower respiratory infection among under five children, Yeka Sub City, Addis Abeba, Ethiopia. PhD Thesis, Addis Ababa University; 2017.

23. Tsegay T, Biyadgie W. Association of indoor air pollution and other risk factors with acute respiratory infections among children in Sheka Zone, South West Ethiopia. J Harmon Res Med Health Sci 2018;5:01.

24. Dessalegn B. Household fuel use and acute respiratory infection among younger children: An exposure assessment in Shebedino Woreda, Southern Ethiopia. PhD Thesis, AAU Electronic Library [unpublished]; 2012.

25. Mekuriaw A, Kassahun A, Sharma HR, Zemicheal G, Abera S. Household fuel use and acute respiratory infections in children under five years of age in Gondar city of Ethiopia. J Environt Earth Sci 2014;4:77-85.

26. WHO. Global Health Observatory: Causes of Child death. 2016.availabel from: https://www.who.int/data/gho/data/ themes/topics/indicator-groups/indicator-group-details/GHO/ causes-of-child-death

27. Mishra V. Indoor air pollution from biomass combustion and acute respiratory illness in preschool age children in Zimbabwe. Int J Epidemiol 2003;32:847-53.

28. Walke SP, Das R, Acharya AS, Pemde HK. Incidence, pattern, and severity of acute respiratory infections among infants and toddlers of a peri-urban area of Delhi: a 12-month prospective study. Int. Sch Res Notices 2014;2014:165152.

29. Hasan M, Tasfina S, Haque SR, Saif-Ur-Rahman K, Khalequzzaman M, Bari W, et al. Association of biomass fuel smoke with respiratory symptoms among children under 5 years of age in urban areas: results from Bangladesh Urban Health Survey, 2013. Environ Health Prev Med 2019;24:65.

30. Seidu AA, Dickson KS, Ahinkorah BO, Amu H, Darteh EKM, Kumi-Kyereme A. Prevalence and determinants of acute lower respiratory infections among children under-five years in subSaharan Africa: evidence from demographic and health surveys. SSM Popul Health 2019;8:100443.

31. Biswal B, Dwidedi B, Pal BB, Kar SK. Prevalence of acute respiratory infection and the associated risk factors: A study of children under five years of age in tribal and coastal areas of Odisha, India. Indian $J$ Public Health Res Develop 2019;10:774-9.

32. Kumar SG, Majumdar A, Kumar V, Naik BN, Selvaraj K, Balajee K. Prevalence of acute respiratory infection among under-five children in urban and rural areas of puducherry,
India. J Nat Sci Biol Med 2015;6:3.

33. World Bank [Internet]. Ethiopia electricity access rural expansion project, phase II - GPOBA. [Accessed: 2020 May 2. Available from: https://projects.worldbank.org/en/projectsoperations/project-detail/P105651?lang=en

34. Federal Democratic Republic of Ethiopia, Ministry of Health. Health Sector Development Programme IV 2010/11-2014/15. 2010. Available from: https://www.uhc2030.org/fileadmin/ uploads/ihp/Documents/Country_Pages/Ethiopia/Ethiopia_HS DP IV_Final_\%202010\%20-2015.pdf

35. Central- Statistical Agency/Ethiopia, ICF International. Ethiopia Demographic and Health Survey 2011. Addis Ababa, Ethiopia: Central Statistical Agency and ICF International. 2012.

36. Central Statistical Agency/Ethiopia, ICF International. Ethiopia Demographic and Health

Survey 2016. Addis Ababa, Ethiopia: Central Statistical Agency and ICF International. 2016.

37. Central Statistical Agency/Ethiopia, ORC Macro. Ethiopia Demographic and Health Survey 2005. Addis Ababa, Ethiopia: Central Statistical Agency and ORC Macro. 2006.

38. Kilabuko JH, Nakai S. Effects of cooking fuels on acute respiratory infections in children in Tanzania. Int $\mathrm{J}$ Environ Res Public Health 2007;4:283-8.

39. Pinzón-Rondón ÁM, Aguilera-Otalvaro P, Zárate-Ardila C, Hoyos-Martínez A. Acute respiratory infection in children from developing nations: a multi-level study. Paediatr Int Child Health 2016;36:84-90.

40. Ujunwa F, Ezeonu C. Risk Factors for acute respiratory tract infections in under-five children in Enugu Southeast Nigeria. Ann Med Health Sci Res 2014;4:95-9.

41. Savitha M, Nandeeshwara S, Kumar MP, Raju C. Modifiable risk factors for acute lower respiratory tract infections. Indian J Pediatr 2007;74:477-82.

42. Fakunle G, Ana G, Ayede A. Environmental risk factors for acute respiratory infections in hospitalized children under 5 years of age in Ibadan, Nigeria. Paediatr Int Child Health 2014;34:120-4.

43. Tazinya AA, Halle-Ekane GE, Mbuagbaw LT, Abanda M, Atashili J, Obama MT. Risk factors for acute respiratory infections in children under five years attending the Bamenda Regional Hospital in Cameroon. BMC Pulm Med 2018;18:7.

44. Koirala R. Risk factors of acute respiratory infections in children under five years attending the Fishtail Hospital, Pokhara, Nepal. J Gandaki Med Coll-Nepal 2019;12:74-9.

45. Acharya P, Mishra SR, Berg-Beckhoff G. Solid fuel in kitchen and acute respiratory tract infection among under five children: evidence from Nepal demographic and health survey 2011. J Commun Health 2015;40:515-21.

46. Acharya D, Prasanna K, Nair S, Rao R. Acute respiratory infections in children: a community based longitudinal study in south India. Indian J Public Health 2003;47:7-13.

47. Rana J, Uddin J, Peltier R, Oulhote Y. Associations between indoor air pollution and acute respiratory infections among under-five children in Afghanistan: Do SES and sex matter? Int J Environ Res Public Health 2019;16:2910.

48. Desai MA, Mehta S, Smith KR, WHO. Indoor smoke from solid fuels: assessing the environmental burden of disease at national and local levels. 2004. Available from: https://apps.who.int/iris/handle/10665/42885

49. Sood A. Indoor fuel exposure and the lung in both developing and developed countries: an update. ClinChest Med 2012;33:649-65

50. Fick Jr RB, Paul ES, Merrill WW, Reynolds HY, Loke JS. 
Alterations in the antibacterial properties of rabbit pulmonary macrophages exposed to wood smoke. Am Rev Respir Dis 1984;129:76-81.

51. Samet JM, Utell MJ. The risk of nitrogen dioxide: what have we learned from epidemiological and clinical studies? Toxicol Industr Health 1990;6:247-62.

52. Thomas PT, Zelikoff JT. Air pollutants: modulators of pulmonary host resistance against infection. In: ST Holgate, HS Koren, JM Samet, RL Maynard, Editors. Air Pollution and Health. Amsterdam, Elsevier; 1999. p. 357-79.

53. Ahmed JA, Katz MA, Auko E, Njenga MK, Weinberg M, Kapella BK, et al. Epidemiology of respiratory viral infections in two long-term refugee camps in Kenya, 2007-2010. BMC Infect Dis 2012;12:7.

54. Chen Y, Kirk M. Incidence of acute respiratory infections in Australia. Epidemiol Infect 2014;142:1355-61.

55. Lawn JE, Cousens S, Zupan J, Team LNSS. 4 million neonatal deaths: when? Where? Why? Lancet 2005;365:891-900.

56. Azad KMAK. Risk factors for acute respiratory infections
(ARI) among under-five children in Bangladesh. J Sci Resh 2009;1:72-81.

57. Akinyemi JO, Morakinyo OM. Household environment and symptoms of childhood acute respiratory tract infections in Nigeria, 2003-2013: a decade of progress and stagnation. BMC Infect Dis 2018;18:296.

58. Joshi S. Solid biomass fuel: indoor air pollution and health effects. Kathmandu Univ Med J 2006;4:141-2.

59. SNV Ethiopia, Ethio Resource Group (ERG), MEGEN Power (MGP). Review of policies and strategies related to the clean cooking sector in Ethiopia. 2018. Available from: https://snv. $\mathrm{org} / \mathrm{cms} / \mathrm{sites} / \mathrm{default} /$ files/explore/download/eth-seeccsreview_of_policies_and_strategies_final_report.pdf

60. Beyene GE, Kumie A, Edwards R, Troncoso K. Opportunities for transition to clean household energy in Ethiopia: application of the household energy assessment rapid tool (HEART). Geneva: World Health Organization; 2018.

Received for publication: 20 August 2020. Accepted for publication: 13 October 2020.

This work is licensed under a Creative Commons Attribution-NonCommercial 4.0 International License (CC BY-NC 4.0).

(C) Copyright: the Author(s), 2020

Licensee PAGEPress, Italy

Multidisciplinary Respiratory Medicine 2020; 15:710

doi:10.4081/mrm.2020.710 